\title{
High resolution topo-bathymetric and flow measurements and 2D- hydrodynamic numerical modelling to evaluate the effects of the deepening of the navigation channel in the Western Scheldt
}

\author{
Yves Plancke ${ }^{1,2} \&$ Dries Vertommen ${ }^{3} \&$ Kirsten Beirinckx ${ }^{4} \&$ Gwendy Vos ${ }^{2,5}$ \\ ${ }^{1}$ Antwerp Maritime Academy, Belgium, Noordkasteel Oost 6, BE-2030 Antwerp; TEL \\ +32.3.224.61.56; email: yves.plancke@mow.vlaanderen.be \\ ${ }^{2}$ Flanders Hydraulics Research, Belgium, Berchemlei 115, BE-2140 Antwerp; TEL \\ +32.3.224.61.56; email: yves.plancke@mow.vlaanderen.be \\ ${ }^{3} \mathrm{MDK}$ - Flemish Hydrography, Belgium, Tavernierkaai 3, BE-2000 Antwerp; TEL: +32.3. \\ 222.08.45; email: dries.vertommen@mow.vlaanderen.be \\ ${ }^{4}$ MOW - Maritime Access, Belgium, Tavernierkaai 3, BE-2000 Antwerp; TEL: \\ +32.3.222.08.81; email: Kirsten.Beirinckx@mow.vlaanderen.be \\ ${ }^{5}$ ANTEA, Belgium, Posthofbrug 10, BE-2600 Antwerp; TEL: +32.3.224.61.81; email: \\ gwendy.vos@mow.vlaanderen.be
}

Topic J: accurate hydrodynamnics

\section{ABSTRACT}

To guarantee optimal port accessibility, one of the projects within the scope of the LongTermVision for the Scheldt estuary to be executed, is the deepening of the navigation channel. In 2001 the Port of Antwerp Expert Team proposed a new disposal strategy, using dredged material to reshape eroded sandbar. A pilot study near the Walsoorden sandbar resulted in the positive evaluation of the feasibility of this new idea. Within the project of deepening of the navigation channel, this new idea was formulated in one of the alternatives. The environmental impact assessment and an appropriate assessment concluded that a new disposal strategy should be applied: the dredged material had to be disposed near sandbars at 4 locations, to create new ecological valuable habitats.

To evaluate the success of this new disposal strategy an extensive monitoring programme was set up . Frequent (2-weekly up to two-monthly) topo-bathymetric surveys using multibeam echo sounding are performed in combination with seasonal sedimentation-erosion measurements using both RTK (intertidal) and singlebeam (subtidal). Also flow velocities on 10 transects, each consisting of 4 measurements points, in the shallow subtidal and the intertidal zone near the disposal locations are monitored using ADCP's (Nortek - AquaDopp). The ADCP devices on the intertidal zone are dug in the sandbar and look upward, allowing maximal vertical resolution when flooded during the tidal cycle.

Parallel with the monitoring, a validated 2D-numerical hydrodynamic model is used to evaluate the effects of the disposal of sediments. Every three months, a simulation is performed using the most recent topo-bathymetry. This allows an evaluation of the changes in flow velocities and flow patterns near the disposal areas.

A special "protocol" (see Depreiter et al., 2012) with several criteria was developed to evaluate the monitoring results and the success of the new disposal strategy. 


\section{A LONG TERM VISION FOR THE SCHELDT-ESTUARY}

In 1999, Flanders and the Netherlands agreed to set up a common strategy for managing the Scheldt estuary. In 2001, both parties signed a memorandum of understanding in which was defined a "Long Term Vision" (LTV) strategy and its objectives. The LTV focusses on the 3 main functions of the estuary: (1) safety against flooding, (2) port accessibility and (3) nature.

The preservation of physical characteristics of the Scheldt-estuary is a crucial aspect in the LTV goals. One of these characteristics of the Western Scheldt is a dynamic flood and ebb channel network, the so-called "multi-channel system" (figure 1). The present trend, a continuation of past natural morphological evolutions combined with human interference (land reclamation and polder building, dredging and other river works) may jeopardise this objective. With the further deepening of the navigation channel, the preservation of the multi-channel system was an important precondition.

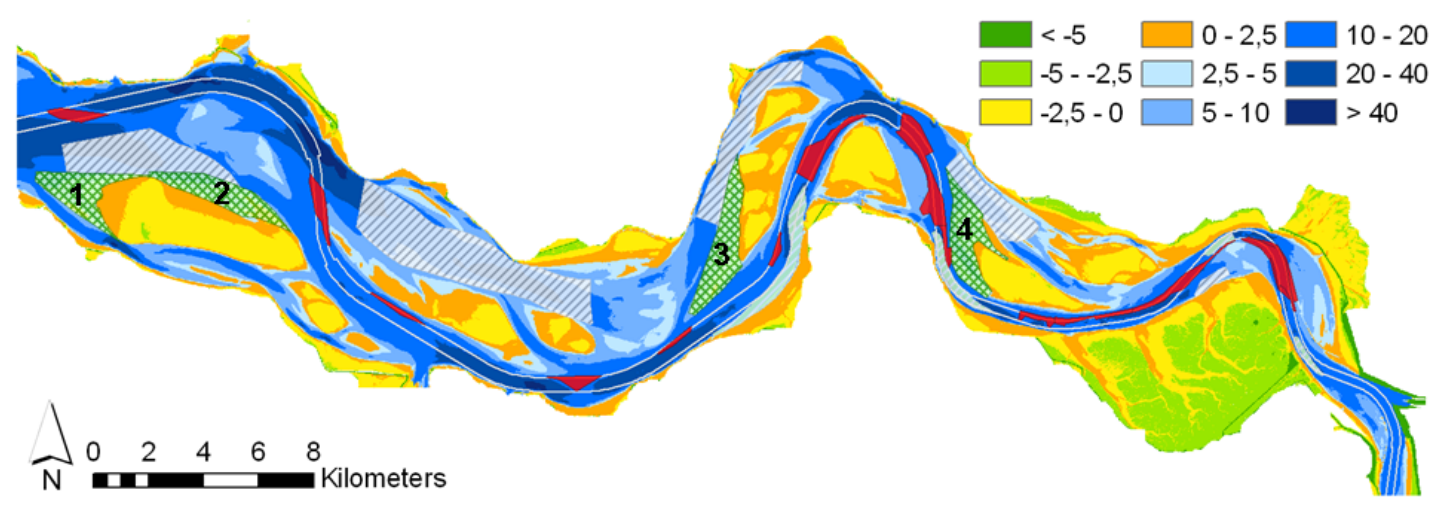

Figure 1: Western Scheldt with disposal locations near sandbars (green hatch) and in channels (white hatch) | 1 -Hooge Platen West | 2 -Hooge Platen North |3-Rug van Baarland | 4-Walsoorden sandbar

\section{A NEW DISPOSAL STRATEGY IN THE SCHELDT-ESTUARY}

The sustainability of the traditional disposal strategy, where dredged material was disposed in secondary channels, was questioned. In 2001, an expert team appointed by the Antwerp Port Authority stated the need for morphological management, aiming at steering the estuarine morphology. In a first phase, sediment from dredging works could be used to reshape eroded sandbars where needed, in order for the flood and ebb flows to continue maintaining the multi-channel system.

A pilot study near the Walsoorden sandbar (figure 1 - location 4) was started in 2002, investigating the feasibility of the new disposal strategy [Plancke et al., 2010]. Extended research (2002-2003), execution (2004 + 2006) and monitoring (2004-2005 + 2006-2008) of two in situ disposal tests concluded that the new disposal strategy was feasible. The monitoring focussed both on morphology as on ecology. The ecological part consisted out of grain size and benthos analysis, using the "BACl"technique (Before-After-Control-Impact).

For monitoring the morphology, multibeam-echo soundings were performed on a regular basis. A special dual-head multibeam was used, to be able to monitor both the 
deeper parts of the zone of interest and the shallow water zones near the sandbars. From the start of the experiment (November 2004) until March 2005, weekly surveys were executed in an area around the disposal location (area 900 ha). From March until June 2005 the measurement frequency was reduced to one survey every 2 to 3 weeks, while from June 2005 until January 2006 one survey per month was executed. Beside this possible impact area, a larger zone was measured every 2 months, to capture possible larger scale influence of the in situ test. These surveys allowed volume computations for the control area. The evolution of the sediment volume is shown in Figure 2. The amount of disposed sediment was measured in the hopper. These amounts were then corrected taking into account the differences in density in the hopper and in situ. A correction factor equal to 0.9 was chosen based on experience.. During the first 2 months the volume within the control area was even higher than after execution of the test, probably due to natural processes. Afterwards a decrease of volume was measured, a loss of $\sim 10 \%$ after 6 months, almost $20 \%$ after one year. The main part of the eroded sand is transported during flood towards the Walsoorden sandbar (Figure 3). This evolution is in agreement with the predictions of the feasibility study. It was concluded that the disposed sediments stay well in place, and the imposed criterion was successfully fulfilled.

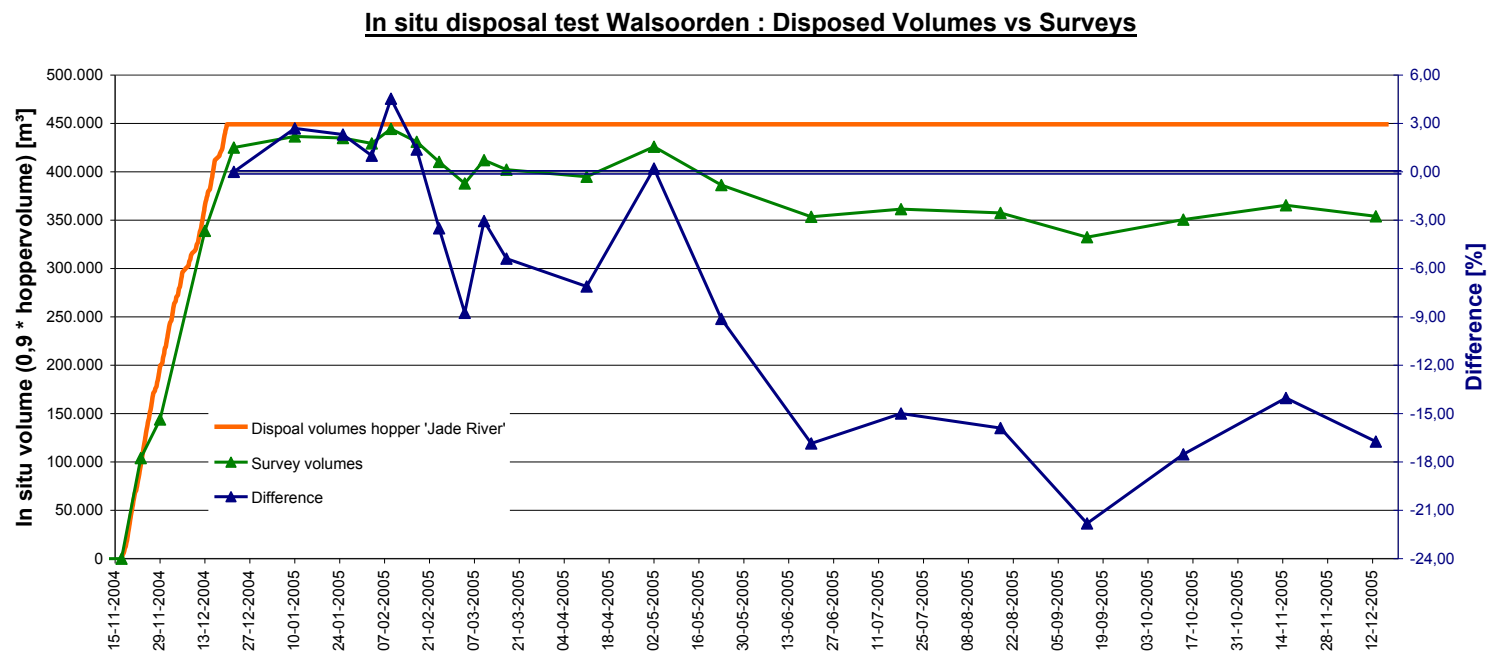

Figure 2: Evolution of measured volumes (orange: disposed; green: measured; blue: difference)

Due to the success of both in situ tests, the strategy of morphological relocation was proposed as one of the alternatives investigated within the environmental impact assessment study for the deepening of the navigation channel. The assessment concluded that the continuation of the traditional disposal strategy could lead, on the long term, to a degeneration of the multi-channel system. On the other hand, the use of the new morphological disposal strategy could create new valuable areas for ecology without endangering the multi-channel system. Within this new strategy, dredged material is seen as a means to create ecological benefits ("working for nature"), thereby mitigating uncertainties surrounding the effects of the channel deepening. The new disposal strategy will create ca. 100 ha of new ecological valuable habitat after 5 years. The final appropriate assessment concluded that no significant negative impact should be expected, due to this new strategy. 

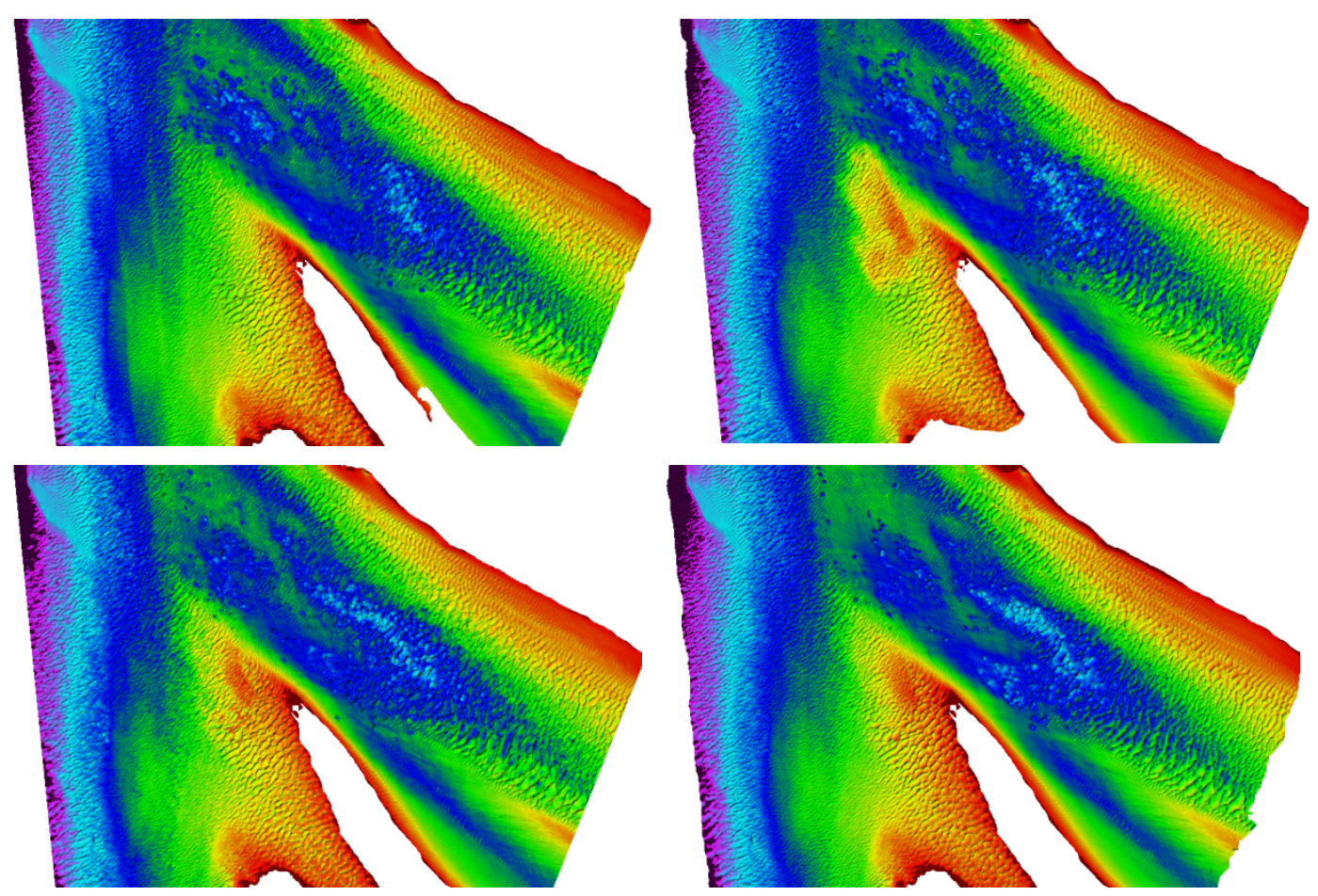

Figure 3: Evolution of bathymetry (November-December 2004 (top), June-December 2005 (down))

Further research was performed by Flanders Hydraulics Research to elaborate the disposal strategy at the 4 new locations. The goal for the new disposal strategy is to maximize the creation of ecological valuable ecotopes, i.e. subtidal and intertidal areas with low currents. The experience gained near the Walsoorden sandbar was used to investigate the optimal disposal strategy at these locations. Therefore an extensive research program was carried out, using field measurements (both GPSfloats and sediment transport) and hydrodynamic numerical models. An extra model validation was performed for the flow velocities on the intertidal area of the sandbars, to improve the correspondence of the patterns of ecological valuable habitats.

The study revealed that fundamental differences exist between the 4 proposed locations (figure 1). On one hand both the locations near the Walsoorden sandbar and the Hooge Platen West are located near the seaward tip of a sandbar, attacked by flood currents. It is expected that sediment disposed at these locations will gradually be transported towards the sandbar. On the other hand the locations near Rug van Baarland and Hooge Platen North are located along a sandbar, guiding the currents. It is expected that sediment disposed at these locations, will be transported along the sandbar.

For the Walsoorden sandbar and the Hooge Platen West (figure 4) the disposal strategy aims at creating a subtidal "megadune" which will migrate towards the sandbar under influence of the flood-dominated currents. This can be seen as an application of the "working with nature" principle. This so-called megadune aims for the creation of an underwater barrier which will reduce the currents between the barrier and the sandbar, creating a low dynamic shallow water area. 
Near Rug van Baarland (figure 4) and Hooge Platen North the disposal strategy aims at constructing a "sand spit" near the tip of the sandbar. This new sand spit, in combination with the existing one, aims for the creation of an underwater barrier reducing the currents between the barrier and the sandbar, creating a low dynamic shallow water area.
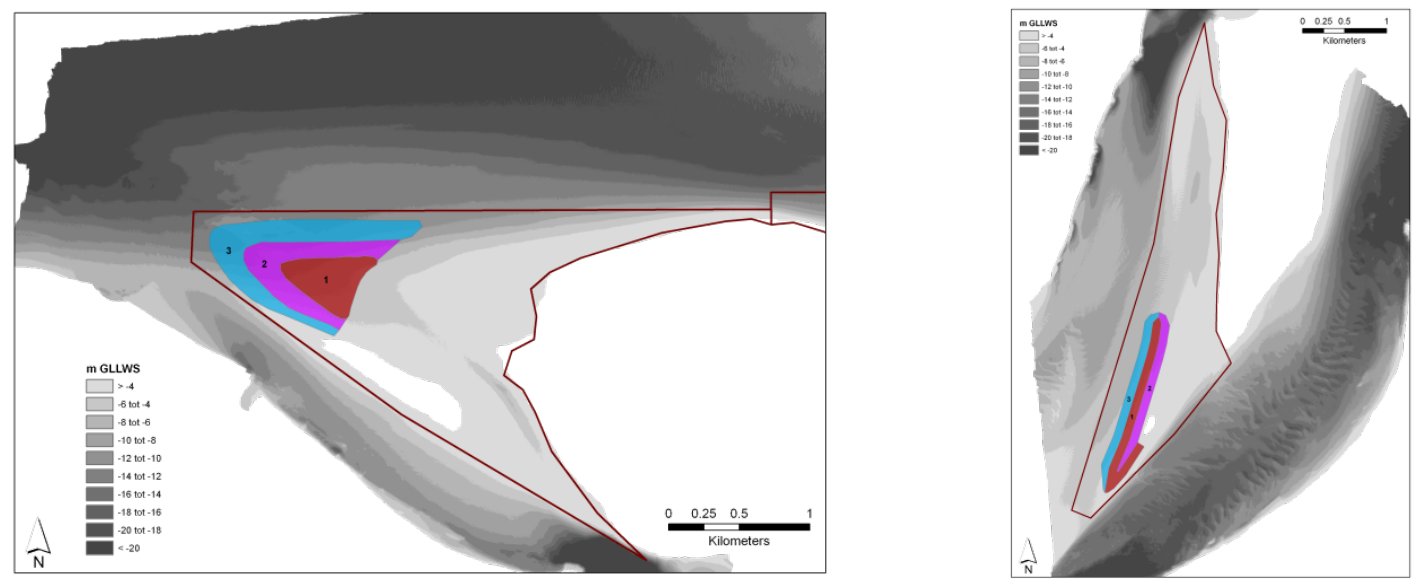

Figure 4: Megadune proposed at Hooge Platen West (left) and sand spit proposed at Baarland (right)

\section{EXECUTION AND EVALUATION OF THE NEW DISPOSAL STRATEGY}

On February $12^{\text {th }} 2010$ dredging works for the enlargement of the navigation channel in the Western Scheldt started. During a period of one year all necessary capital dredging works $\left(7,7 \mathrm{Mm}^{3}\right.$ of sandy material) were executed. The sediments were disposed near the 4 proposed locations along sandbars. In the deeper areas near the sandbars, the disposal was performed using the conventional "clapping" technique with hoppers. In the shallower areas, the trailing suction hopper dredgers connected to a floating line which was connected to a diffuser (figure 5). This technique allowed the disposal of sandy material in zones up to $2 \mathrm{~m}$ below low water. Simultaneously with the capital dredging works, maintenance dredging works had to take place. Part $(20 \%)$ of the dredged sediments from the maintenance works, are disposed near the sandbars, while the other part is disposed in the main or secondary channels. From February $12^{\text {th }} 2010$ until February $12^{\text {th }} 2012$ (the first 2 years) a total of $12.4 \mathrm{Mm}^{3}$ of sediments have been disposed near all 4 sandbars, which is $63 \%$ of the amount foreseen to be disposed in 5 years (table 1).

To evaluate the possible effects of the deepening of the navigation channel and the new disposal strategy, an extensive monitoring programme "MONEOS-T" [Schrijver et al., 2008] was set up. This monitoring programme consists among others of high frequent multi-beam and single-beam echo soundings, current measurements and RTK height measurements.

Before the start of the deepening, the reference situation was monitored for all parameters. Since the start of the works, new measuring campaigns at all locations have been executed to evaluate the effects of the disposal activities. During the next years this monitoring will continue, allowing the evaluation of the new disposal strategy on the longer term. 


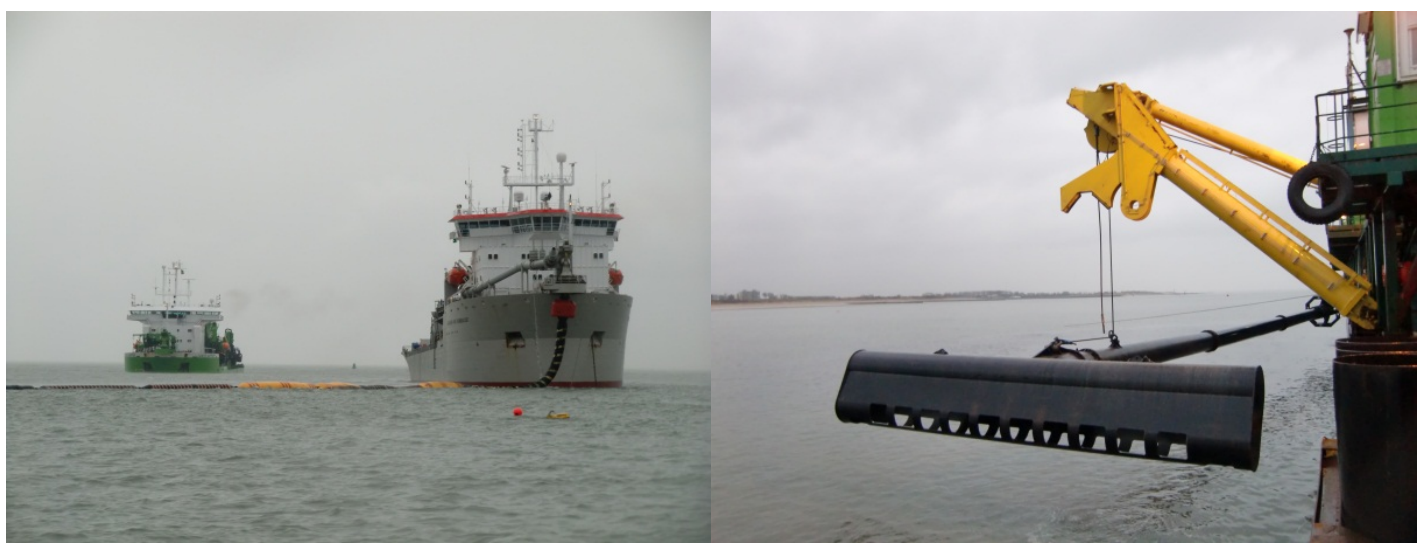

Figure 5: TSHD connected to floating line (left) and detail of diffuser head (right)

To monitor the stability of the disposed sediment, high frequent multi-beam echo soundings (MBES) of the total disposal area were performed. In the period during the execution and 1 month after the last disposal, one sounding every 2 weeks was made. After this period, the intensity was reduced to one sounding per month and finally to one every 2 months. Additionally to these "disposal zone" soundings, a MBES of a larger area took place twice a year to monitor the morphological changes in case the sediment would be transported out of the disposal zone. Based on these echo sounding maps, the stability of the disposed material is calculated, showing that the stability is different at the four locations (Table 1). It should be mentioned that the location near the Rug van Baarland is characterised by an important natural sedimentation, additional to the deposited sediment.

Table 1: Overview of quantities to be disposed near sandbars and initial stability

\begin{tabular}{|c|c|c|c|c|c|}
\hline Location & $\begin{array}{c}\text { Capacity } \\
\text { over 5 yr } \\
{\left[\mathrm{Mm}^{3}\right]}\end{array}$ & $\begin{array}{c}\text { Disposal } \\
\text { Year 1 } \\
{\left[\mathrm{Mm}^{3}\right]}\end{array}$ & $\begin{array}{c}\text { Disposal } \\
\text { Year 2 } \\
{\left[\mathrm{Mm}^{3}\right]}\end{array}$ & $\begin{array}{c}\text { Disposal } \\
\text { Year 1+2 } \\
{\left[\mathrm{Mm}^{3}\right]}\end{array}$ & $\begin{array}{c}\text { Stability } \\
{[\%]}\end{array}$ \\
\cline { 1 - 3 } Hooge Platen West & \multirow{2}{*}{8.20} & 1.95 & 0.58 & 2.53 & 70 \\
\cline { 1 - 1 } Hooge Platen North & 3.50 & 0.51 & 4.01 & 105 \\
\cline { 1 - 1 } Rug van Baarland & 5.00 & 0.70 & 0.58 & 1.28 & 268 \\
\hline Walsoorden sandbar & 6.50 & 3.72 & 0.82 & 4.54 & 62 \\
\hline
\end{tabular}

The flow velocities are measured by Rijkswaterstaat on 10 transects over 2 full spring-neap-tide cycles. Each transect consists of 3 points in the intertidal area (measured with Nortek AquaDopp | $2 \mathrm{MHz}$ - figure 6) and 1 undeep subtidal point (RDI ADCP | $1200 \mathrm{kHz}$ ). The AquaDopps in the intertidal zone were dug in the sandbar and look upward, allowing maximal vertical resolution when flooded during the tidal cycle. To present measurement data, scatterplots are generated showing the maximum flow velocity (flood or ebb) versus the tidal range (rising or falling) (figure 6). The scatterplots show that at certain measuring points, located in the 'shadow' of the mega dunes, the flow velocities have decreased. Besides these measurements, a 
calibrated 2D-numerical model [Ides et al., 2010] is used to evaluate the developments of the flows near the sandbars. Simulations are performed on regular basis (every $3-6$ months), using the most actual topo-bathymetry near the sandbars. All 40 measurement points are defined in the model and similar analyses is performed. Additionally, spatial maximum flow maps are generated and changes in these maps are evaluated (figure 6).

A special "protocol" (see Depreiter et al., 2012), containing several morphological (stability of disposed material) and ecological (evolution of ecotopes) criteria was appended to the disposal license to, quasi continuously, evaluate the monitoring data. An independent group of experts ("Commission Monitoring Western Scheldt") supervises the evaluation of the monitoring and advices at least every 2 years on the disposal strategy.
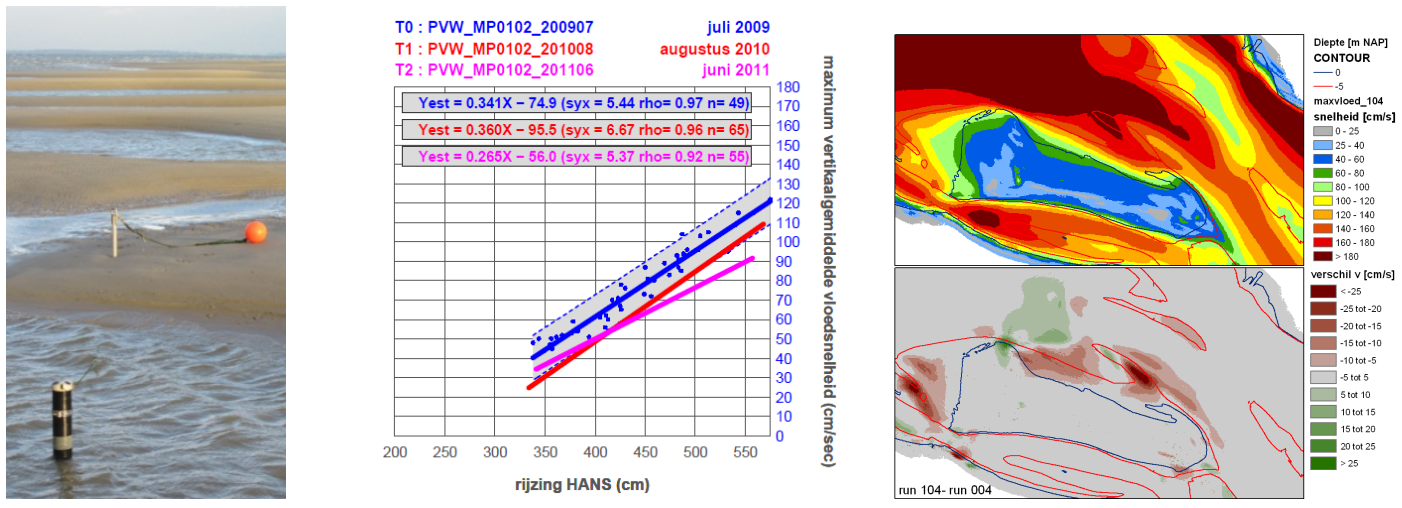

Figure 6: AquaDopp (left), scatterplot from ADP-measurement rising vs. maximum flood velocity (mid) and flood velocities and difference $(T 0+15$ months $-T 0)$ from numerical model (right)

\section{CONCLUSION}

Within the enlargement project of the navigation channel in the Scheldt-estuary, a new disposal strategy was chosen, aimed at creating new ecological valuable habitats. An extensive monitoring programme was set up to evaluate the success of this new strategy, focusing on topo-bathymetry (using MBES) and flow characteristics (using Acoustical Doppler techniques). Additionally, hydrodynamic numerical simulations were performed to investigate the changes in flow patterns near the disposal locations. The first results show different effects near different sandbars. The extensive monitoring programme makes it possible to understand the changes on a short term, and to adapt the relocation strategy based on analyses of the monitoring results if necessary. The continuation of the monitoring and the analysis of the data will allow a final evaluation 5 years after the start of enlargement project.

\section{REFERENCES}

Depreiter, D.; Sas, M.; Beirinckx, K.; Liek, G.J. (2012). Flexible Disposal Strategy: monitoring as a key to understanding and steering environmental responses to dredging and disposal in the Scheldt Estuary. Hydro2012 - Taking care of the sea, Rotterdam, Netherlands. 
Ides, S.; Plancke, Y.; Vos, G. (2010). Validation of a 2D hydrodynamic model within a study to propose the optimal disposal strategy inthe Western Scheldt, in: SIMHYDRO 2010: modèles hydrauliques et incertitudes, Nice, France.

Plancke, Y.; Ides, S.; Vos, G.; Roose, F.; Peters, J.J. (2010). A new disposal strategy for the Western Scheldt, conciliating port accessibility and nature preservation, in:32nd PIANC Congress, 125th anniversary PIANC - setting the course, Liverpool, UK.

Schrijver, M.; Plancke, Y. (2008). Execution of the monitoringplan MONEOS-T (In Dutch: Uitvoeringsplan MONEOS-T 2008-2018). Rijkswaterstaat Zeeland, Middelburg, Waterbouwkundig Laboratorium, Antwerpen. 